\title{
金属融剂を用いたクロムホウ化物結晶の合成
}

\author{
岡田 繁・工藤邦男*・飯泉清賢**・久高克也**
}

神奈川大学工学部応用化学科, 221 横浜市神奈川区六角橋 3-27-1

*神奈川大学工学部機械工学科, 221 横浜市神奈川区六角橋 3-27-1

**東京工芸大学工学部工業化学科, 243-02 厚木市飯山 1583

\section{Preparation of Chromium Boride Crystals Obtained from High-Temperature Metal Solutions}

\author{
Shigeru OKADA, Kunio KUDOU*, Kiyokata IIZUMI ${ }^{* *}$ and Katsuya KUDAKA** \\ Department of Applied Chemistry, Faculty of Engineering, Kanagawa University, \\ 3-27-1, Rokkakubashi, Kanagawa-ku, Yokohama-shi 221 \\ *Department of Mechanical Engineering, Faculty of Engineering, Kanagawa University, \\ 3-27-1, Rokkakubashi, Kanagawa-ku, Yokohama-shi 221 \\ **Department of Industrial Chemistry, Faculty of Engineering, Tokyo Institute of Polytechnics, 1583, Iiyama, Atugi-shi 243-02
}

[Received March 7, 1994; Accepted June 14, 1994]

Chromium boride crystals were obtained by the hightemperature metal (copper, lead or tin) solutions us= ing chromium metal and boron powders as starting materials in an argon atmosphere. $\mathrm{Cr} B$ and $\mathrm{Cr}_{2}$ crystals were obtained as a single phase, however, $\mathrm{Cr}_{3} \mathrm{~B}_{4}$ and $\mathrm{Cr}_{2} \mathrm{~B}_{3}$ were obtained invariably as a phase mixture for various atomic ratios of the starting material in molten metal solutions. The largest $\mathrm{CrB}$ and $\mathrm{Cr}_{2}$ crystals were obtained from Cu solution. CrB crystals were obtained in the form of pillar shape extending to $a$-axis or $c$-axis and thin plates with well-developed $\{010\}$ faces, and $\mathrm{CrB}_{2}$ crystals were obtained in the form of nearly spherical polyhedron. The largest crystals prepared had the maximum dimensions of about 0.12 $\mathrm{mm} \times 0.13 \mathrm{~mm} \times 3.30 \mathrm{~mm}$ for $\mathrm{Cr} B$ and $30 \mu \mathrm{m}$ for $\mathrm{Cr}_{2}$. The results of unit cell dimension and chemical analysis of $\mathrm{CrB}$ and $\mathrm{Cr}_{2} \mathrm{~B}_{2}$ crystals are also present.

Key-words : Chromium boride, Molten metal solution, Crystal size, Morphology

\section{1. 緒 言}

クロムーホウ素 2 成分系には o- $\mathrm{Cr}_{2} \mathrm{~B}, \mathrm{t}-\mathrm{Cr}_{2} \mathrm{~B}, \mathrm{Cr}_{5} \mathrm{~B}_{3}, \mathrm{CrB}$, $\mathrm{Cr}_{3} \mathrm{~B}_{4}, \mathrm{Cr}_{2} \mathrm{~B}_{3}, \mathrm{CrB}_{2}, \mathrm{CrB}_{4}$ の 8 種類の化合物が知られてい る1)〜5)。これらの内で, $\mathrm{CrB}, \mathrm{Cr}_{3} \mathrm{~B}_{4}$ 及び $\mathrm{CrB}_{2}$ は耐熱性, 耐薬品性，耐摩耗性に優れ，金属的な電気伝導性を示す化 合物であるために各分野から期待されている．クロムホウ 化物の合成方法には，金属クロムとホウ素の直接合成が， 広く用いられているが，上記のような組成比の異なるクロ ムホウ化物を単一相として得るためには，直接合成では困 難な場合が多(3),4),6)。そこで，本報告では著者らの過去 の研究結果から,クロムホウ化物を単一相として得る方法 として金属融剤法が適していると考えて実験を行った．使 用した金属融剂は報告例のない，銅，鉛及びスズを用い て，クロムーホウ素 2 成分系の化合物を単一相として得る ための合成条件を金属融剂ごとに検討した。その結果，そ れぞれの金属融剤から $\mathrm{CrB}$ 及び $\mathrm{CrB}_{2}$ は，結晶の大きさ
の異なる単一相として得られた，特に，銅融剤を用いた場 合には比較的大きな $\mathrm{CrB}$ と $\mathrm{CrB}_{2}$ 結晶が単一相として得 られたので，その合成条件を調へた，また，各金属融剂か ら得られた $\mathrm{CrB} と \mathrm{CrB}_{2}$ 結晶は形態と大きさの恋化を調 べ，格子定数值と組成分析の測定を行った．得られた結果 について以下に報告する。

\section{2. 実験方法}

原料としては金属クロム粉末（レアメタリック製，純度 99.9\%, 200 mesh 以下), 非晶質ホウ素（レアメタリック 製，純度 $96.8 \%$ )，金属融剂として粒状の銅（三津和化学 薬品製，純度 $99.99 \%$ ），粒状の鉛（キシダ化学製，純度 99.99\%) と粒状のスズ（昭和化学製，純度99.99\%) を所 定の配合原子比（以下配合比と称する）（表 1 ）になるよ うに混合し，高純度アルミナ製タンマン管（純度99.8\%） に充填した。なお，金属融剤量は予備実験の結果から表 1のように定めた。これをアルゴンガス䨌囲気中で，加熱 処理して結晶を合成した。加熱温度は $1200 \sim 1500^{\circ} \mathrm{C}, 5$ ～ 50 時間保持し, 徐冷速度は室温屯で $50^{\circ} \mathrm{C} / \mathrm{h}$ の一定条件で 行った，冷却後，結晶を取り出すために過剩の金属融剂を 酸溶液で処理して結晶を取り出した。得られた結晶につい ては粉末 X 線回折計と Guinier-Hägg 集中法カメラで相 の同定と格子定数值を測定した，結晶の大きさと形態は走 査型電子顕微鏡（SEM；日本電子製，JSM-35C）と実体 顕微鏡で調べた。結晶の組成分析は ICP 発光分光分析装 置（島津製作所製，ICP-50型）で，結晶中の不純物ある いは組成比の変化はX線マイクロプローブ (EPMA；日 本電子製，JSM-35C) で検討した。

\section{3. 実験結果と考察}

銅融剂を用いた場合 加熱温度 $1500^{\circ} \mathrm{C}, 10$ 時間保持, 銅 融剂量 $\mathrm{Cu} / \mathrm{Cr}=16.36$ の一定条件で, ホウ素配合比 B/ $\mathrm{Cr}=1.0 \sim 3.0$ で検討した， そのときのX 線回折から得ら れたクロムホウ化物の生成割合の変化を図 1 に示す。図 
Table 1. Preparation Conditions of Chromium Boride Crystals from Molten Metal Solutions

\begin{tabular}{|c|c|c|c|c|c|}
\hline $\begin{array}{l}\text { Run } \\
\text { No. }\end{array}$ & $\begin{array}{l}\text { Comp } \\
\text { (atomi }\end{array}$ & $\begin{array}{l}\text { posit } \\
\text { ic ra } \\
B\end{array}$ & $\begin{array}{l}\text { on of starting materials } \\
\text { o) } \\
\text { metal solution }(\mathrm{Cu}, \mathrm{Pb}, \mathrm{Sn})\end{array}$ & $\begin{array}{c}\text { Temperature } \\
\left({ }^{\circ} \mathrm{C}\right)\end{array}$ & Phases identificd \\
\hline 1 & 11. & 1.0 & $16.36(\mathrm{Cu})$ & 1500 & CrB, unknown (1) \\
\hline 2 & 11. & 1.1 & $16.36(\mathrm{Cu})$ & 1500 & $\mathrm{CrB}$ \\
\hline 3 & $\begin{array}{ll}1 & 1 . \\
1 & 1\end{array}$ & 1.2 & $\begin{array}{l}16.36(\mathrm{Cu}) \\
16.36(\mathrm{Cu})\end{array}$ & $\begin{array}{l}1500 \\
1500\end{array}$ & $\begin{array}{l}\mathrm{CrB} \\
\mathrm{CrB}_{3} \mathrm{Cr}_{2} \mathrm{~B}\end{array}$ \\
\hline 4 & 11. & 1.3 & $16.36(\mathrm{Cu})$ & 1500 & $\mathrm{CrB}, \mathrm{Cr}_{3} \mathrm{~B}_{4}$ \\
\hline 5 & 11. & 1.4 & $16.36(\mathrm{Cu})$ & 1500 & $\mathrm{CrB}, \mathrm{Cr}_{3} \mathrm{~B}_{4}$ \\
\hline 6 & 11 & 1.5 & $16.36(\mathrm{Cu})$ & 1500 & $\mathrm{CrB}, \mathrm{Cr}_{3} \mathrm{~B}_{4}$ \\
\hline 7 & 11 & 1.6 & $16.36(\mathrm{Cu})$ & 1500 & $\mathrm{CrB}, \mathrm{Cr}_{3} \mathrm{~B}_{4}$ \\
\hline 8 & 11 & 1.7 & $16.36(\mathrm{Cu})$ & 1500 & $\mathrm{Cr}_{3} \mathrm{~B}_{4}, \mathrm{CrB}, \mathrm{CrB}_{2}$ \\
\hline 9 & 11 & 1.8 & $16.36(\mathrm{Cu})$ & 1500 & $\mathrm{Cr}_{3} \mathrm{~B}_{4}, \mathrm{CrB}, \mathrm{CrB}_{2}$ \\
\hline 10 & 11 & 1.9 & $16.36(\mathrm{Cu})$ & 1500 & $\mathrm{Cr}_{3} \mathrm{~B}_{4}, \mathrm{CrB}, \mathrm{CrB}_{2}$ \\
\hline 11 & 12 & 2.0 & $16.36(\mathrm{Cu})$ & 1500 & $\mathrm{CrB}_{2}, \mathrm{Cr}_{3} \mathrm{~B}_{4}, \mathrm{CrB}$ \\
\hline 12 & 12 & 2.2 & $16.36(\mathrm{Cu})$ & 1500 & $\mathrm{CrB}_{2}, \mathrm{Cr}_{3} \mathrm{~B}_{6}$, unknown (2) \\
\hline 13 & 12 & 2.4 & $16.36(\mathrm{Cu})$ & 1500 & $\mathrm{CrB}_{2}$, unknown (2) \\
\hline 14 & 12 & 2.5 & $16.36(\mathrm{Cu})$ & 1500 & $\mathrm{CrB}_{2}$, unknown (2) \\
\hline 15 & 12 & 2.6 & $16.36(\mathrm{Cu})$ & 1500 & $\mathrm{CrB}_{2}$ \\
\hline 16 & 12 & 2.8 & $16.36(\mathrm{Cu})$ & 1500 & $\mathrm{CrB}_{2}$ \\
\hline 17 & 13 & 3.0 & $16.36(\mathrm{Cu})$ & 1500 & $\mathrm{CrB}_{2}$ \\
\hline $\begin{array}{l}18 \\
19\end{array}$ & $\begin{array}{ll}1 & 1 . \\
1 & 1 .\end{array}$ & $\begin{array}{l}1.0 \\
1.5\end{array}$ & $\begin{array}{l}5.01(\mathrm{~Pb}) \\
5.01(\mathrm{~Pb})\end{array}$ & $\begin{array}{l}1500 \\
1500\end{array}$ & $\begin{array}{l}\mathrm{CrB}^{\mathrm{Cr}_{3} \mathrm{~B}_{4}, \mathrm{Cr}_{2} \mathrm{~B}_{3}}\end{array}$ \\
\hline 20 & 12. & 2.0 & $5.01(\mathrm{~Pb})$ & 1500 & $\mathrm{CrB}_{2}$ \\
\hline 21 & 12 & 2.5 & $5.01(\mathrm{~Pb})$ & 1500 & $\mathrm{CrB}_{2}$ \\
\hline 22 & 13 & 3.0 & $5.01(\mathrm{~Pb})$ & 1500 & $\mathrm{CrB}_{2}$ \\
\hline $\begin{array}{l}23 \\
24\end{array}$ & $\begin{array}{ll}1 & 1 \\
1 & 1 \\
1 & 2\end{array}$ & 1.0 & $\begin{array}{l}7.66(\mathrm{Sn}) \\
7.66(\mathrm{Sn}) \\
7.66(\mathrm{Sn})\end{array}$ & $\begin{array}{l}1500 \\
1500 \\
1500\end{array}$ & $\begin{array}{l}\mathrm{CrB} \\
\mathrm{CrB} \\
\mathrm{CrB}_{3}, \mathrm{Cr}_{2} \mathrm{~B}\end{array}$ \\
\hline 25 & 12 & 2.0 & $7.66(\mathrm{Sn})$ & 1500 & $\mathrm{CrB}_{2}, \mathrm{Cr}_{3} \mathrm{~B}_{4}$ \\
\hline 26 & 12 & 2.5 & $7.66(\mathrm{Sn})$ & 1500 & $\mathrm{CrB}_{2}$ \\
\hline 27 & 13 & & $7.66(\mathrm{Sn})$ & 1500 & $\mathrm{CrB}_{2}$ \\
\hline
\end{tabular}

The starting materials for Run Nos. 1 to 17 of $2.00 \mathrm{~g} \mathrm{Cr}, 0.415$ to $1.247 \mathrm{~g}$ boron and $40.0 \mathrm{~g} \mathrm{Cu}$; the starting materials for Run Nos. 18 to 22 consist of $2.00 \mathrm{~g} \mathrm{Cr}, 0.415$ to $1.247 \mathrm{~g}$ boron and $40.0 \mathrm{~g}$ $\mathrm{Pb}$ : the starting materials for Run Nos. 23 to 27 consist of $2.00 \mathrm{~g} \mathrm{Cr}, 0.415$ to $1.247 \mathrm{~g}$ boron and $40.0 \mathrm{~g} \mathrm{Sn}$. The time for which the raw material was kept at this temperature was $10 \mathrm{~h}$ in all cases.

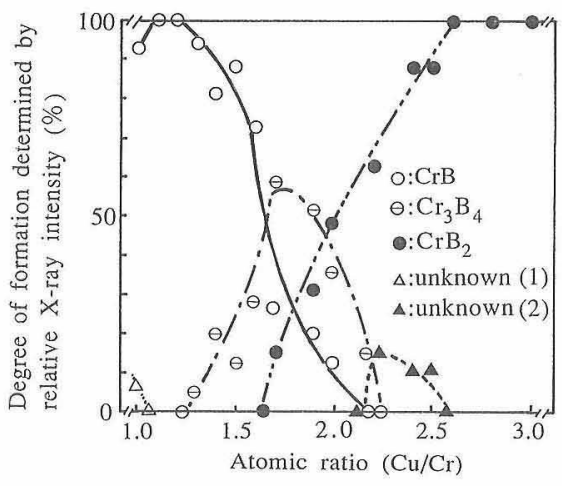

Fig. 1. Relative X-ray intensity of each phase in the products obtained from several starting materials with various atomic ratios $(\mathrm{B} / \mathrm{Cr})$. The atomic ratio $\mathrm{Cu} / \mathrm{Cr}$ is fixed at 16.36 . The starting materials are soaked at $1500^{\circ} \mathrm{C}$ for $10 \mathrm{~h}$.

$\mathrm{O}: \mathrm{CrB}, \ominus: \mathrm{Cr}_{3} \mathrm{~B}_{4}, \bigcirc: \mathrm{CrB}_{2}$,

$\triangle$ : unknown (1), $\triangle$ : unknown (2).

1 と表 1 かから，ホウ素配合比 $\mathrm{B} / \mathrm{Cr}=1.0$ では $\mathrm{CrB}$ と末知 物質 (unknown(1))が混合相として得られたが, ホウ素 配合比 $\mathrm{B} / \mathrm{Cr}=1.1 \sim 1.2$ では $\mathrm{CrB}$ が単一相として得られ た。また，ホウ素配合比 $\mathrm{B} / \mathrm{Cr}=1.3 \sim 1.6$ では $\mathrm{CrB}$ と $\mathrm{Cr}_{3} \mathrm{~B}_{4}$ が混合相として得られたが, ホウ素配合比 $\mathrm{B} /$ $\mathrm{Cr}=1.7 \sim 2.0$ では $\mathrm{CrB}, \mathrm{Cr}_{3} \mathrm{~B}_{4}$ と $\mathrm{CrB}_{2}$ が混合相として得ら れた. 更に; ホウ素配合比 $\mathrm{B} / \mathrm{Cr}=2.2$ では $\mathrm{CrB}_{2}$ と $\mathrm{Cr}_{3} \mathrm{~B}_{4}$ が混合相として得られたが，木ウ素配合比 $\mathrm{B} / \mathrm{Cr}=2.4$ 〜 3.0では $\mathrm{CrB}_{2}$ が単一相として得られることが分かった。 以上の結果から, 上記の合成条件では $\mathrm{CrB}, \mathrm{Cr}_{3} \mathrm{~B}_{4}$ 及び
$\mathrm{CrB}_{2}$ の 3 種類のクロムホウ化物が生成したが，その内で $\mathrm{CrB}$ と $\mathrm{CrB}_{2}$ がそれぞれ単一相として得られることが分 加た。 たたし， O- $\mathrm{Cr}_{2} \mathrm{~B}, \mathrm{t}-\mathrm{Cr}_{2} \mathrm{~B}, \mathrm{Cr}_{5} \mathrm{~B}_{3}, \mathrm{Cr}_{2} \mathrm{~B}_{3}$ と $\mathrm{CrB}_{4}$ の 化合物, 又は $\beta$-菱面体型ホウ素にクロム元素が固溶した $\left.\mathrm{CrB}_{\sim 41}{ }^{7}\right)$ や $\mathrm{Cu}-\mathrm{B}$ 系 $\left(\mathrm{CuB}_{x}(x=23 \sim 28)^{8), 9)}\right)$ 及び $\mathrm{Cr}-\mathrm{Cu}-$ $\mathrm{B}$ 系化合物（現在のところ報告例はない）も予期されたが X線回折からは同定できなかった。

鉛及びスズ融剤を用いた場合 表 1 から，両融片とも $\mathrm{CrB}$ と $\mathrm{CrB}_{2}$ が単一相で得られたが，それらの結晶の大き さは 5 10 $\mu \mathrm{m}$ 程度と小さい，一方，これらの融剤から $\mathrm{Cr}_{3} \mathrm{~B}_{4}$ あるいは $\mathrm{Cr}_{2} \mathrm{~B}_{3}$ も生成したが，これらの結晶は銅融 剤の場合と同様に単一相としては得られなかった。また， それら以外のクロムホウ化物， $\mathrm{Pb}-\mathrm{B}$ 系と $\mathrm{Cr}-\mathrm{Pb}-\mathrm{B}$ 系化 合物（両者とも現在のところ報告例はない）, Sn-B 亲と $\mathrm{Cr}-\mathrm{Sn}-\mathrm{B}$ 系化合物（両者とも現在のところ報告例はない） はX線回折から同定できなかった。

また，結晶の大きさは，銅融剤から得られたクロムホウ 化物の方が鉛又はス文融剤から得られた結晶より大きい。 これは，高温での金属融剤中への各元素の溶解度の違いで 理解することがでさる、Cu-B 系状態図10)汃ら，銅中に小 ウ素の溶解量は 0.29 at\%であるのに対して, $\mathrm{Pb}-\mathrm{B}$ 系及び Sn-B 系の状態図10)方ら，鉛及びスズ中にホウ素の溶解量 が極端に少ないことからも推察できる.

銅融剤から得られた $\mathrm{CrB}$ 結晶の写真を図 $2(\mathrm{~A})$ (棒状結 晶）と図 2 (B) (板状結晶) に示す。これから， CrB は此 較的大きな結晶が得られたが，それは $a$ 軸又は $c$ 軸方向に 成長した最大 $0.12 \mathrm{~mm} \times 0.13 \mathrm{~mm} \times 3.30 \mathrm{~mm}$ の棒状結晶あ るいは $\{010\}$ 面のよく発達した最大 $0.03 \mathrm{~mm} \times 0.50$ $\mathrm{mm} \times 1.80 \mathrm{~mm}$ の板状結晶であった。一方, 銅融剂から得 られた $\mathrm{CrB}_{2}$ 結晶の SEM 写真を図 3 に示す。これから, $\mathrm{CrB}_{2}$ は最大で $30 \mu \mathrm{m}$ であり, その形態は $\{1 \overline{1} 00\},\{1 \overline{1} 01\}$ と\{0001\}面が現れた六方多面体状結晶であった。

$\mathrm{CrB}$ 及び $\mathrm{CrB}_{2}$ が単一相として得られた結晶を用いて格 子定数值と化学分析の測定を行った。その結果, 格子定数 值は先の文献值 ${ }^{11)}(\mathrm{CrB}: a=0.2977$ (2) $\mathrm{nm}, b=0.7862$ (3) $\mathrm{nm}, c=0.2931(1) \mathrm{nm} ; \mathrm{CrB}_{2}: a=0.2973(1) \mathrm{nm}, c=0.3074$ (1) $\mathrm{nm}$ ）と比較的よく一致していた．また，化学分析で は, 各融剤加ら得られた $\mathrm{CrB}$ と $\mathrm{CrB}_{2}$ 結晶は組成比変化 がほとんどなく，化学量論組成を有していることが分かっ た。

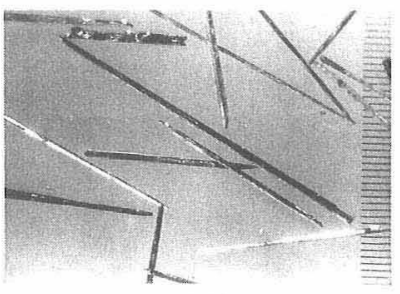

(A)

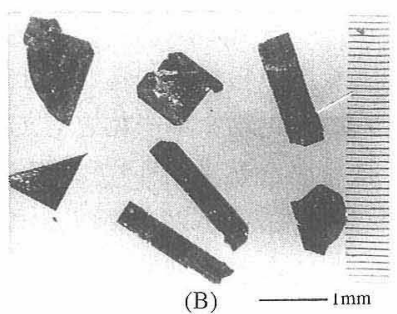

(B)
Fig. 2. Microphotographs of CrB crystals. CrB crystals obtained from molten copper solution. The starting materials are soaked at $1500^{\circ} \mathrm{C}$ for $10 \mathrm{~h}$.

(A) : Pillar crystals, (B) : Plate-like crystals. 


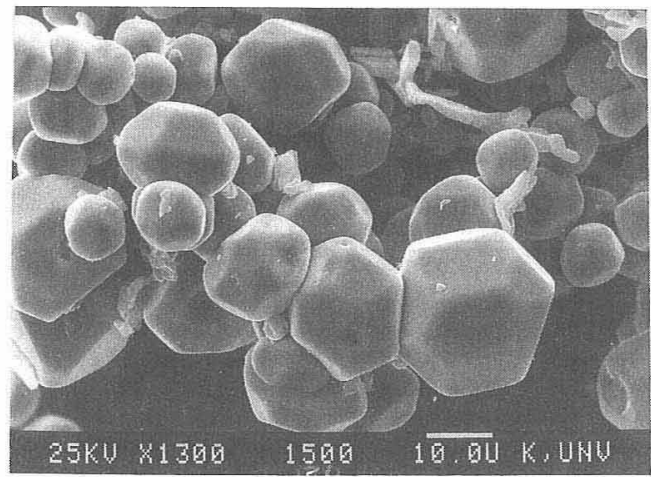

Fig. 3. SEM photograph of $\mathrm{CrB}_{2}$ crystals. $\mathrm{CrB}_{2}$ crystals obtained from molten copper solution. The starting materials are soaked at $1500^{\circ} \mathrm{C}$ for $10 \mathrm{~h}$.

\section{4. 結 論}

アルゴンガス雾囲気中，銅，鉛及びスズの金属融剂中 で，金属クロム粉末と非晶質ホウ素の反応からクロムホウ 化物結晶を合成した，得られた結果は以下のと抢りであ る。

（1）銅，鉛及びスズ融剤から得られたクロムホウ化物 の内で, $\mathrm{CrB}$ と $\mathrm{CrB}_{2}$ 結晶は単一相として合成できる。

（2）鉛及びスズ融剂から得られた $\mathrm{CrB}$ と $\mathrm{CrB}_{2}$ 結晶は 5〜10 $\mu \mathrm{m}$ 程度の大きさである.
（3）銅融剤から得られた $\mathrm{CrB}$ と $\mathrm{CrB}_{2}$ 結晶の大きさは， $\mathrm{CrB}$ 結晶では最大 $0.12 \mathrm{~mm} \times 0.13 \mathrm{~mm} \times 3.30 \mathrm{~mm}$ で， $a$ 軸又は $c$ 軸方向に成長した棒状結晶，あるいは $\{010\}$ 面の よく発達した板状結晶であるが， $\mathrm{CrB}_{2}$ 結晶では最大 30 $\mu \mathrm{m}$ で, 球状に近い六方多面体状結晶である.

\section{文献}

1) G. V.Samsonov, "Plenum Press Handbook of High-Temperature Materials", Vol. 2, Plenum Press (1964) p. 81.

2) S. Andersson and T. Lundström, Acta Chem. Scand., 22, 3103-09 (1968).

3) T. Lundström, Arkiv Kemi, 31, 227-30 (1969).

4) C. N. Guy and A. A. Uraz, J. Less-Common Metals, 48, 199204 (1976).

5) S. Okada, T. Atoda, I. Higashi and Y. Takahashi, J. LessCommon Met., 113, 331-39 (1985).

6）飯泉清賢, 吉川展和, 河野恵子, 岡田 繁, 久高克也, $\mathrm{T}$. Lundström, 日化, 1992, 1320-25.

7) S. Andersson and T. Lundström, J. Solid State Chem., 2, 603-11 (1970).

8) I. Higashi, T. Sakurai and T. Atoda, J. Less-Common Metals, 45, 283-92 (1976).

9) S. Andersson and T. Lundström, J. Solid State Chem., 10, 219-24 (1974).

10) T. B. Massalski, "Binary Alloy Phase Diagrams", Vol. 1, Second ed., The Materials Information Society (1990) pp. 474-539.

11) S. Okada, T. Atoda and I. Higashi, J. Solid State Chem., 68, 61-67 (1987). 